\title{
Diagnosing COPD: advances in training and practice - a systematic review
}

This article was published in the following Dove Press journal:

Advances in Medical Education and Practice

4 April 2016

Number of times this article has been viewed

\author{
Vladimir Koblizek ${ }^{1,2}$ \\ Barbora Novotna ${ }^{1-3}$ \\ Zuzana Zbozinkova ${ }^{3}$ \\ Karel Hejduk ${ }^{3}$ \\ 'Department of Pneumology, \\ University Hospital Hradec Kralove, \\ Hradec Králové, Czech Republic; \\ ${ }^{2}$ Faculty of Medicine in Hradec \\ Kralove, Charles University in Prague, \\ Hradec Králové, Czech Republic; \\ ${ }^{3}$ Institute of Biostatistics and \\ Analyses, Faculty of Medicine, Masaryk \\ University, Brno, Czech Republic
}

Correspondence: Vladimir Koblizek Department of Pneumology, University Hospital Hradec Kralove, Charles University in Prague, Faculty of Medicine in Hradec Kralove, Sokolska 58I, 50005 Hradec Králové, Czech Republic Tel +420 49583477 I Email vladimir.koblizek@fnhk.cz
Abstract: Chronic obstructive pulmonary disease (COPD) is a chronic inflammatory lung syndrome, caused by long-term inhalation of noxious gases and particles, which leads to gradual airflow limitation. All health care professionals who care for COPD patients should have full access to high-quality spirometry testing, as postbronchodilator spirometry constitutes the principal method of COPD diagnosis. One out of four smokers 45 years or older presenting respiratory symptoms in primary care, have non-fully reversible airflow limitation compatible with COPD and are mostly without a known diagnosis. Approximately 50.0\%-98.3\% of patients are undiagnosed worldwide. The majority of undiagnosed COPD patients are isolated at home, are in nursing or senior-assisted living facilities, or are present in oncology and cardiology clinics as patients with lung cancers and coronary artery disease. At this time, the prevalence and mortality of COPD subjects is increasing, rapidly among women who are more susceptible to risk factors. Since effective management strategies are currently available for all phenotypes of COPD, correctly performed and well-interpreted postbronchodilator spirometry is still an essential component of all approaches used. Simple educational training can substantially improve physicians' knowledge relating to COPD diagnosis. Similarly, a physician inhaler education program can improve attitudes toward inhaler teaching and facilitate its implementation in routine clinical practices. Spirometry combined with inhaled technique education improves the ability of predominantly nonrespiratory physicians to correctly diagnose COPD, to adequately assess its severity, and to increase the percentage of correct COPD treatment used in a real-life setting. Keywords: education, inhaled technique, overdiagnosis, primary care, spirometry, underdiagnosis

\section{Introduction Definition}

Chronic obstructive pulmonary disease (COPD) is a common preventable and treatable disease, characterized by persistent airflow limitation, which is usually progressive and associated with an enhanced chronic inflammatory response in the airways and the lung to noxious particles or gases. Exacerbations and comorbidities contribute to the overall severity in individual patients. ${ }^{1} \mathrm{COPD}$ is not a name of a single disease but an umbrella denomination used to describe chronic inflammatory lung syndrome, primarily caused by long-term harmful inhalation and leading to gradual airflow limitation - bronchial obstruction. The traditional medical terms chronic bronchitis and emphysema are now part of the COPD diagnosis, as most COPD subjects encountered in practice share both of these features. ${ }^{1-3}$ The most common symptoms of COPD are submit your manuscript | www.dovepress.com Dovepress http://dx.doi.org// 0.2147/AMEP.S76976 
breathlessness with decreased physical activity and cough., COPD is not just a "smoker's cough" but an underdiagnosed pulmonary disorder that may progressively lead to significant impairment of quality of life and premature death. ${ }^{6}$

\section{Prevalence of COPD}

COPD constitutes a respiratory affliction of high prevalence with an explosively growing mortality and an immense global socioeconomic impact. The PLATINO study found that the prevalence of COPD in the population aged 40 years or older was $15.8 \% .^{7}$ At the same time, $26 \%$ of adults with a prolonged ( $\geq 30$ years) smoking history had been labeled as having COPD in South Carolina, US. ${ }^{5}$ Recent studies estimated the COPD prevalence to be $5 \%-25 \% .{ }^{8,9}$ General incidence of COPD varies widely from $1.5 \%$ to $11 \% .^{10,11}$ Epidemiological variability could be attributed to the different risk factors, genetic heterogeneity of population, and the criteria used for spirometry confirmation of COPD. ${ }^{8,12}$ The World Health Organization estimates COPD to become the third leading cause of death by 2030, and the burden of COPD is projected to further increase in the coming decades due to continued exposure to risk factors and aging of the global population. ${ }^{6}$ Even though most of the information available on COPD prevalence, morbidity, and mortality comes from high-income countries, accurate epidemiologic data on COPD are difficult and expensive to collect. Nevertheless, the vast majority $(90 \%)$ of estimated COPD deaths occur in low- and middle-income countries. ${ }^{6}$ In the Czech Republic (with a population of $>10.5$ million), the recently estimated prevalence is $7 \%-8 \% ; \sim 16,000$ patients are hospitalized each year as a result of COPD, and >3,500 die annually. ${ }^{13}$

\section{Who is at risk?}

In general, a strong genetic component in conjunction with an environmental insult accounts for the development of COPD. While the predominant risk factor is tobacco smoke (including passive smoke exposure), other factors such as age, a previous history of bronchial asthma, polygenetic predisposition, and frequent lower respiratory infections in childhood are significant. ${ }^{1,6}$ Environmental and occupational exposures to dusts and chemicals (such as vapors, irritants, and fumes) and household indoor biomass fumes also substantially contribute to the development of COPD, particularly in low-income countries. Fumes from biomass fuels used indoors by households account for the high prevalence of COPD in nonsmoking women in parts of the Middle East, Africa, and South Asia. ${ }^{6}$ Globally, $~ 50 \%$ of all households and $90 \%$ of rural households use solid fuels (coal and biomass) as the main domestic source of energy, thus exposing $\sim 50 \%$ of the world population, close to three billion people, to the harmful effects of these combustion products. ${ }^{14} \mathrm{~A}$ fraction of COPD cases are attributable to work and are estimated as $19.2 \%$ overall and $31.1 \%$ among never smokers in the US population-based Third National Health and Nutrition Examination Survey. ${ }^{15}$ In the past, COPD was more common in men, but because of increased tobacco use among women in high-income countries, more prominent susceptibility to harmful components of tobacco smoke, and the higher risk of exposure to indoor biomass fuel in low-income countries, the disease currently affects men and women almost equally. $5,6,16$

\section{Problem of underrecognition of COPD COPD diagnosis - why early?}

COPD remains significantly underdiagnosed, with correct diagnosis commonly missed or delayed until the pulmonary impairment is advanced. Nonspecific clinical features of early disease are the main reason for this lag. A clinical diagnosis of COPD should be considered in any patient who has breathlessness, chronic cough or sputum production, and a history of exposure to risk factors for the disease. ${ }^{1}$ Many patients have been labeled wrongly as simple "smokers" cough, repeated lower respiratory tract infections and/ or asthma. However, it is contemplated that early diagnosis of COPD should have a positive impact on individual and population outcomes. Especially, earlier smoking cessation and avoiding other environmental and occupational risk factors before the devastating phase of COPD syndrome should be the critical point of successful management of all patients. Inhaled bronchodilators (BDs), regular physical activity, and other specific medical interventions are also able to favorably modify the natural course of early disease..$^{1,3,5}$

\section{COPD diagnosis - spirometry}

The cornerstone of the current approach to diagnosis of COPD lies within the evaluation of a patients' lung functions, symptoms, history of exacerbations, and clinical phenotype assessment. ${ }^{1,17}$ Validity of the diagnosis should always be checked using spirometry. Spirometry is widely recommended as a screening method of all symptomatic individuals, especially in subjects with a long-term risk exposure. ${ }^{18}$ The essential pathophysiological requirement for COPD diagnosis is the presence of a post-BD expiratory airflow limitation, which 
is defined, according to the current European Respiratory Society (ERS) statement, as a decrease in the forced expiratory volume in 1 second $\left(\mathrm{FEV}_{1}\right) /$ vital capacity $(\mathrm{VC})$ ratio below the lower limit of normal (LLN) values. ${ }^{19,20}$ Worldwide, the strategy of the Global Initiative for Chronic Obstructive Lung Disease (GOLD) appointed the presence of post-BD

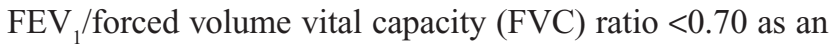
unsophisticated indicator of persistent airflow limitation - the most important pulmonary function feature of COPD subjects. ${ }^{1}$ Globally, the spirometric criterion established by the GOLD is simple, independent of reference values, and has been used in numerous clinical trials. Diagnostic simplicity and consistency are key for the busy nonrespiratory specialist physicians. Nevertheless, ERS statement recommends use of the $\mathrm{FEV}_{1} / \mathrm{VC}$ ratio rather than just the $\mathrm{FEV}_{1} / \mathrm{FVC}$ ratio and the cut-off value of this ratio was set at the 5 th percentile of the normal distribution (LLN) rather than at a fixed value of 0.7. The main advantage of using $\mathrm{VC}$ in place of $\mathrm{FVC}$ is that the ratio of $\mathrm{FEV}_{1}$ to $\mathrm{VC}$ is capable of accurately identifying more obstructive patterns than its ratio to FVC, because FVC is more dependent on flow and volume histories. In contrast with a fixed value of 0.7 , the use of the 5 th percentile (LNN) does not lead to an overestimation of the ventilatory defect in older people (males aged more than 40 and females aged more than 50 years) with no history of exposure to noxious particles or gases. ${ }^{1,19,20}$ The above-mentioned LLN values are based on the normal distribution and classify the bottom $5 \%$ of the healthy population as abnormal (below LLN). However, the LLN values are highly dependent on the choice of valid reference equations. Currently, we would propose the use of GOLD approach in general practices and ERS recommendations in practices of pulmonary specialists. ${ }^{1,18-20}$

\section{COPD diagnosis - exacerbation history}

The most common clinical presentations of COPD are dyspnea, cough, fatigue, and intolerance of physical activity. ${ }^{21-25}$ Dyspnea first occurs during high-intensity activities, subsequently during low-intensity movements, and later even at rest. Breathlessness slowly induces gradual exercise intolerance resulting in physical inactivity, significant life style change, and social isolation of COPD patients. ${ }^{25}$ COPD patients commonly experience a cough, which can be productive in approximately two-thirds of cases or nonproductive. ${ }^{26}$ Long-lasting cough may adversely affect performance in daily life due to its negative effect on fatigue and decrease abdominal muscle endurance in patients with COPD. ${ }^{27}$ The progressive course of COPD could be complicated by episodes of acute worsening called exacerbations, in $25 \%-40 \%$ of subjects. ${ }^{1,28}$ Although most guidelines and clinical trials define COPD exacerbations similarly, there are differences in the exact definition used. Most of them use event-based description of exacerbation, which necessitates an increase in both symptoms and the use of health care resources, and grade exacerbations based on their severity, ie, moderate exacerbations as those requiring treatment with systemic corticosteroids and/or antibiotics and severe exacerbations as those necessitating admission to the hospital. ${ }^{29,30}$ The ERS and the American Thoracic Society task force group simply defined exacerbation as an increase in respiratory symptoms over baseline that usually lead to a change in treatment. ${ }^{31}$

\section{COPD diagnosis - symptoms}

In addition to expiratory airflow limitation quantification and careful taking of exacerbation history, it is recommended to measure COPD symptoms universally, using the COPD Assessment Test (CAT) and/or the modified Medical Research Council (mMRC) dyspnea scale., ${ }^{1,32}$ Using three (airflow limitation, exacerbation frequency and symptoms) parameters, it is possible to classify each patient into one of the four categories denoted A, B, C, and D according to the latest version of GOLD. ${ }^{1,33}$ Cutoff points of mMRC grade $\geq 2$ and CAT score $\geq 10$ were initially established by GOLD as equivalents in determining patients with high symptomatology (GOLD). Category A represents the early stages of the disease. The elimination of all inhalation risks could fundamentally change the prognosis of patients in category A and reduce the overall burden caused by COPD. ${ }^{34,35}$ Category B deserves particular attention as it consists of highly symptomatic patients with a less pronounced lung function deterioration, although they have a significantly higher mortality risk - mainly cardiovascular and malignant causes or the severity of lung emphysema does not strictly correspond to $\mathrm{FEV}_{1}{ }^{36-38}$ Patients with low symptomatology level make up the category C. They can usually be found in the general population, but rarely in the pulmonologist's care. This group of patients can be a smart target for active screening programs, such as category A ${ }^{39}$ Mortality risk of $\mathrm{C}$ patients is moderate or low (significantly lower than in those in the B category). ${ }^{36,37}$ The highest mortality risk is associated with the D category, especially if the classification is made on the basis of frequent exacerbations. ${ }^{40} \mathrm{D}$ subjects are extremely threatened by high respiratory and cardiovascular morbidity and mortality rates; therefore, careful monitoring and treatment of these individuals in the hands of respiratory specialists has to be thorough 


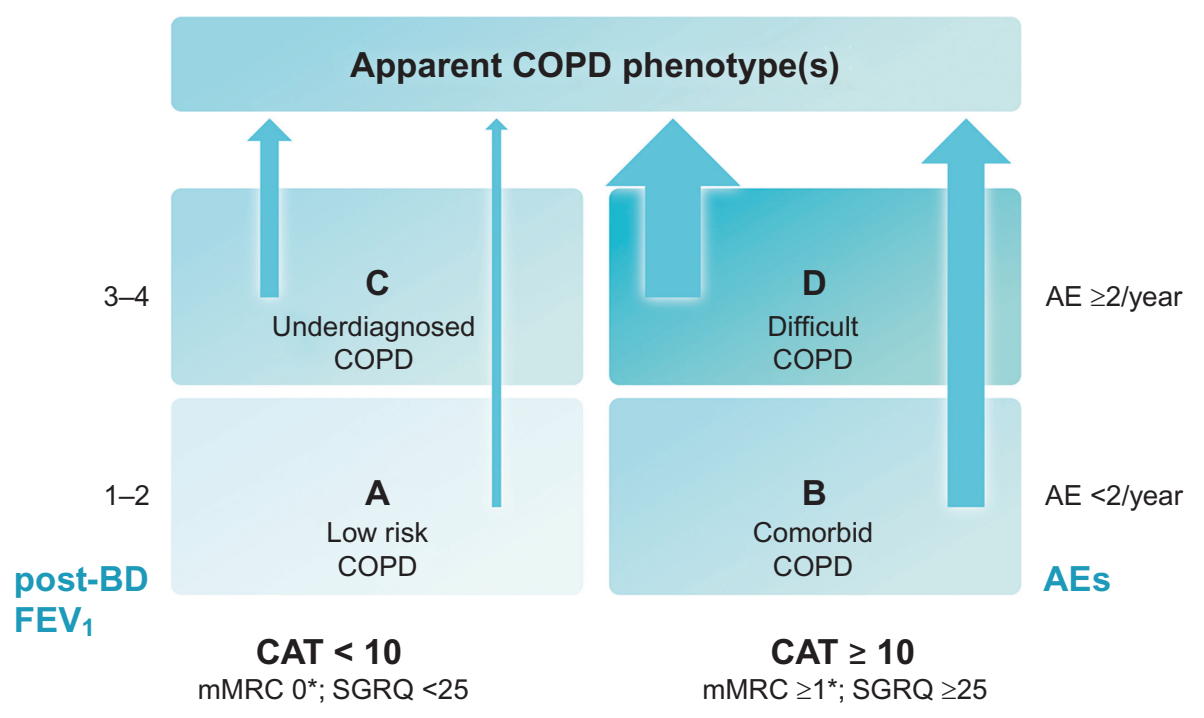

Figure I GOLD A-D categories with slight modification of the Czech Pneumological and Phthisiological Society.

Note: With respect to the current evidence (hospitalization for an exacerbation is associated with a poorer prognosis of COPD individuals), the latest version of GOLD strategy has proposed the addition of "one or more exacerbations leading to hospitalization per year" as the second possible indicator of high-risk patients.' A clinically apparent and visible phenotype should be found in symptomatic (B and D) COPD subjects especially. $42,54 *$ The cutoff points of an mMRC grade $<1$ and CAT score $<10$ were approximately equivalent in determining COPD patients with low symptomatology. Modified from Koblizek V, Chlumsky J, Zindr V, et al; Czech Pneumological and Phthisiological Society. Chronic Obstructive Pulmonary Disease: official diagnosis and treatment guidelines of the Czech Pneumological and Phthisiological Society; a novel phenotypic approach to COPD with patient-oriented care. Biomed Pap Med Fac Univ Palacky Olomouc Czech Repub. 2013;157(2):189-201. doi: I0.5507/bp.20I3.039.54

Abbreviations: AE, acute exacerbation; BD, bronchodilator; CAT, COPD Assessment Test; COPD, chronic obstructive pulmonary disease; FEV, , forced expiratory volume in I second; GOLD, Global Initiative for Chronic Obstructive Lung Disease; mMRC, modified Medical Research Council; SGRQ, St. George's Respiratory Questionnaire.

and comprehensive in every aspect. ${ }^{36}$ Long-term variability of the patient's GOLD classification strongly corresponds with the changes in CAT scores. ${ }^{41}$ The GOLD classification does well in identifying individuals at risk of exacerbations, although the predictive ability for mortality in elderly adults with COPD is not high. ${ }^{37}$ Unfortunately, clinical equivalence of GOLD-proposed symptom's borders between both low and high symptomatic subjects (mMRC scale $\geq 2=$ CAT score $\geq 10$ ) seems to be problematic. ${ }^{42}$ Therefore, possible recalibration of symptom equivalence, and new threshold for COPD symptom assessment (eg, mMRC scale $\geq 1=$ CAT score $\geq 10$ and mMRC scale $\geq 2=$ CAT score $\geq 17$ ), could improve the validity of GOLD categories. ${ }^{43}$ In accordance with data published in 2013 by Jones et al, the Czech Pneumological and Phthisiological Society (CPPS) recommends the use of assessment of these respiratory symptoms with a slight modification of GOLD (Figure 1)..$^{42,44}$

\section{COPD diagnosis - phenotypical heterogeneity}

COPD is a well-known heterogeneous condition with multiple clinical faces. ${ }^{1,2}$ Simplifications cannot express the myriad of forms of this serious syndrome. ${ }^{45-47}$ GOLD documents current new innovations in the approach to treating COPD and provides the right steps toward individualized care of COPD patients. ${ }^{1}$ However, physicians worldwide feel that the clinical variety of this disease greatly exceeds the two-dimensional diagram of dividing the patients into four A-D categories (Figure 1). Each patient is unique., ${ }^{8,48}$ Moreover, GOLD is not designed to be a guideline but to be a strategy or the minimal global diagnosis and treatment requirements. Therefore, it is of no surprise that a number of different countries have published their own national recommendations, sometimes based on the GOLD principles, reflecting the specific local needs and possibilities (Table 1)..$^{1749-54}$ The heterogeneity of COPD can lead to phenotype categorization because not all patients respond to all types of treatments. In terms of treatment, phenotypes were first used in the Spanish COPD recommendations. ${ }^{17}$ The Spanish COPD guidelines (La Guía Española de la EPOC [GesEPOC]) divided COPD into the following four clinically defined groups: infrequent exacerbators, asthma and COPD overlap syndrome (ACOS), frequent exacerbators with a predominance of chronic bronchitis, and frequent exacerbators without the presence of chronic bronchitis (Figure 2). The most controversial variant of COPD is ACOS. The ACOS has been defined as symptoms of increased reversibility of airflow limitation, more eosinophilic bronchial and systemic inflammation, and increased response to inhaled corticosteroids (ICS), compared with the remaining COPD subjects. ACOS patients have more frequent exacerbations, more wheezing and dyspnea, and more intensive health status impairment. ${ }^{49,55}$ The influence of the GesEPOC's guidelines on other national documents is indisputable. ${ }^{17,48,49,55}$ Although this phenotypically targeted approach to COPD subjects is 
Table I Short summary of several recent COPD guidelines

\begin{tabular}{|c|c|c|c|c|c|c|}
\hline \multirow[b]{2}{*}{$\begin{array}{l}\text { Guidelines } \\
\text { parameter }\end{array}$} & \multicolumn{6}{|c|}{ Country, institution } \\
\hline & $\begin{array}{l}\text { Spain, } \\
\text { GesEPOC }\end{array}$ & $\begin{array}{l}\text { Czech Republic, } \\
\text { CPPS }\end{array}$ & $\begin{array}{l}\text { Finland, } \\
\text { FMSD/FRS }\end{array}$ & $\begin{array}{l}\text { India, Indian Chest } \\
\text { Society/NCCP }\end{array}$ & $\begin{array}{l}\text { Saudi Arabia, } \\
\text { STS }\end{array}$ & $\begin{array}{l}\text { Global, } \\
\text { GOLD }\end{array}$ \\
\hline Guided by & Phenotypes alone & $\begin{array}{l}\text { GOLDa and } \\
\text { phenotypes }\end{array}$ & $\begin{array}{l}\mathrm{GOLD}^{\mathrm{b}} \text { and } \\
\text { phenotypes }\end{array}$ & GOLD and phenotypes ${ }^{c}$ & $\begin{array}{l}\text { 'Three phenotypic } \\
\text { classes }^{\text {d }}\end{array}$ & GOLD alone \\
\hline Mainly focused on & $\mathrm{GPs}+\mathrm{PFs}$ & PFs & GPs & GPs & $\mathrm{GPs}+\mathrm{INs}+\mathrm{PFs}$ & $\mathrm{GPs}+\mathrm{PFs}$ \\
\hline Valid since & 2012 & 2013 & 2014 & 2013 & 2014 & 2015 \\
\hline Spirometry post-BD & Mandatory & Mandatory & Mandatory & Mandatory & Mandatory & Mandatory \\
\hline $\begin{array}{l}\text { Airflow limitation } \\
\text { definition }\end{array}$ & $\mathrm{FEV}_{1} / \mathrm{FVC}<0.7$ & $\mathrm{FEV}_{1} / \mathrm{VC}<\mathrm{LLN}$ & $\mathrm{FEV}_{\mathrm{I}} / \mathrm{FVC}<0.7$ & $\mathrm{FEV}_{1} / \mathrm{FVC}<\mathrm{LLN}^{\mathrm{e}}$ & $\mathrm{FEV}_{1} / \mathrm{FVC}<0.7$ & $\mathrm{FEV}_{\mathrm{I}} / \mathrm{FVC}<0.7$ \\
\hline $\begin{array}{l}\text { Frequent exacerbator } \\
\text { means }\end{array}$ & $\geq 2 /$ year & $\geq 2 /$ year & $\begin{array}{l}\geq 2 / \text { year or } \geq 1 / \text { year } \\
\text { leading to hospital } \\
\text { admission }\end{array}$ & $\geq 2 /$ year & $\begin{array}{l}\geq 2 / \text { year or } \geq 1 / \text { year } \\
\text { leading to hospital } \\
\text { admission }\end{array}$ & $\begin{array}{l}\geq 2 / \text { year or } \geq 1 / \text { year } \\
\text { leading to hospital } \\
\text { admission }\end{array}$ \\
\hline $\begin{array}{l}\text { High level of } \\
\text { symptoms }\end{array}$ & $\begin{array}{l}\text { CAT } \geq 10 \\
(\mathrm{mMRC} \text { scale } \geq 2)\end{array}$ & $\begin{array}{l}\text { CAT } \geq 10 \\
(\text { mMRC scale } \geq 1)\end{array}$ & $C A T \geq 10$ & $\begin{array}{l}\text { mMRC scale } \geq 2 \text { (CAT } \\
\geq 10)\end{array}$ & $\mathrm{CAT} \geq 10$ & $\begin{array}{l}\text { CAT } \geq 10 \text { or } \\
\text { mMRC scale } \geq 2\end{array}$ \\
\hline Smoking cessation & Mandatory & Mandatory & Mandatory & Mandatory & Mandatory ${ }^{g}$ & Mandatory \\
\hline BD's role & Mandatory & Mandatory & Mandatory & $\begin{array}{l}\text { Mandatory, } \\
\text { short-acting only, } \\
\text { long-acting for moderate } \\
\text { and severe categories }\end{array}$ & Mandatory & Mandatory \\
\hline ICS role & FAEs or ACOS & FAEs or ACOS & FAEs or ACOS & Severe category & FAEs (Class III) & $\mathrm{C}$ and $\mathrm{D}$ categories \\
\hline $\begin{array}{l}\text { Mucoactive } \\
\text { drugs' role }\end{array}$ & FAEs & $\begin{array}{l}\text { FAEs with chronic } \\
\text { bronchitis, or BCOS }\end{array}$ & FAEs & NR & Optional & D category \\
\hline Long-term ATB role & $\begin{array}{l}\text { FAEs with chronic } \\
\text { bronchitis }\end{array}$ & $\begin{array}{l}\text { FAEs with chronic } \\
\text { bronchitis or with } \\
\text { BCOS }\end{array}$ & NR & NR & NR & NR \\
\hline Methylxanthines role & Optional & Optional & Optional & Optional & Optional & Optional \\
\hline Roflumilast role & $\begin{array}{l}\text { FAEs with chronic } \\
\text { bronchitis and } \\
\mathrm{FEV}_{1}<50 \%\end{array}$ & $\begin{array}{l}\text { FAEs with chronic } \\
\text { bronchitis and } \\
\mathrm{FEV}_{1}<50 \%\end{array}$ & $\begin{array}{l}\text { FAEs with chronic } \\
\text { bronchitis and } \\
\mathrm{FEV}_{1}<50 \%\end{array}$ & Severe category & $\begin{array}{l}\text { FAEs with chronic } \\
\text { bronchitis (Class III) }\end{array}$ & $\begin{array}{l}\text { D GOLD category } \\
\text { with chronic } \\
\text { bronchitis and FEV } \\
<50 \%\end{array}$ \\
\hline Training of inhalation & Mandatory & Mandatory & Mandatory & Mandatory & Mandatory & Mandatory \\
\hline $\begin{array}{l}\text { Regular physical } \\
\text { activity }\end{array}$ & Mandatory & Mandatory & Mandatory & Mandatory & Mandatory & Mandatory \\
\hline $\begin{array}{l}\text { Influenza and } \\
\text { pneumococcal } \\
\text { vaccination }\end{array}$ & Mandatory & Mandatory & Mandatory & Optional & Mandatory & Mandatory \\
\hline
\end{tabular}

Notes: a Czech guidelines use slightly modified GOLD categories. ${ }^{b}$ Finnish guidelines use GOLD I-4 grading (according to post-BD FEV ). ${ }^{\mathrm{c}} \mathrm{Classification}$ of severity of the disease (into three categories) should be done for all COPD patients based on the post-BD FEV pulmonale/secondary polycythemia. ${ }^{\text {TT }}$ Those patients with low risk of exacerbation (less than two in the past year) can be classified as either Class I when they have less symptoms or Class II when they have more symptoms (CAT $\geq 10$ ). High-risk COPD patients, as manifested with more than or equal to two exacerbations or hospitalization in the past year irrespective of the baseline symptoms, are classified as Class III. eln the absence of reference equations for LLN, FEV, /FVC $<0.7$ may be used as the cutoff for defining airflow obstruction. Included Bidi and other indigenous forms of tobacco smoking; exposure to biomass fuel smoke is a strong risk factor for COPD in India. In Included shisha (water pipe). Data from GOLD,' Miravitlles et al, ${ }^{17}$ Kankaanranta et al, ${ }^{51}$ Gupta et al, ${ }^{52}$ Khan et al, ${ }^{53}$ and Koblizek et al. ${ }^{54}$

Abbreviations: ACOS, asthma and COPD overlap; ATBs, antibiotics; BCOS, bronchiectasis and COPD overlap syndrome; BD, bronchodilator; CAT, COPD Assessment Test; CPPS, Czech Pneumological and Phthisiological Society; FAEs, frequent acute exacerbators; FEV , forced expiratory volume in I second; FMSD, Finnish Medical Society Duodecim; FRS, Finnish Respiratory Society; FVC, forced volume vital capacity; GesEPOC, La Guía Española de la EPOC (Spanish COPD Guidelines); GOLD, Global Initiative for Chronic Obstructive Lung Disease; GPs, general practitioners; ICS, inhaled corticosteroids; INs, internists; LLN, the lower limit of normal; mMRC, modified Medical Research Council; NCCP, National College of Chest Physicians (India); NR, not recommended; PFs, pulmonary physicians; STS, Saudi Thoracic Society; VC, vital capacity.

still not widely accepted, the idea of phenotypes has already been adopted by some authors. ${ }^{56}$ However, there is no great consensus on the number of phenotypes and their precise definition; the number can be anywhere from two to 210 million, which is the estimated number of COPD patients worldwide. ${ }^{8}$

\section{COPD underdiagnosis and undertreatment} The real prevalence of COPD is higher than the number of actively assessed and treated COPD subjects, and most COPD individuals still remain undiagnosed and untreated in all parts of the world. ${ }^{1}$ In contrast, a small fraction of 


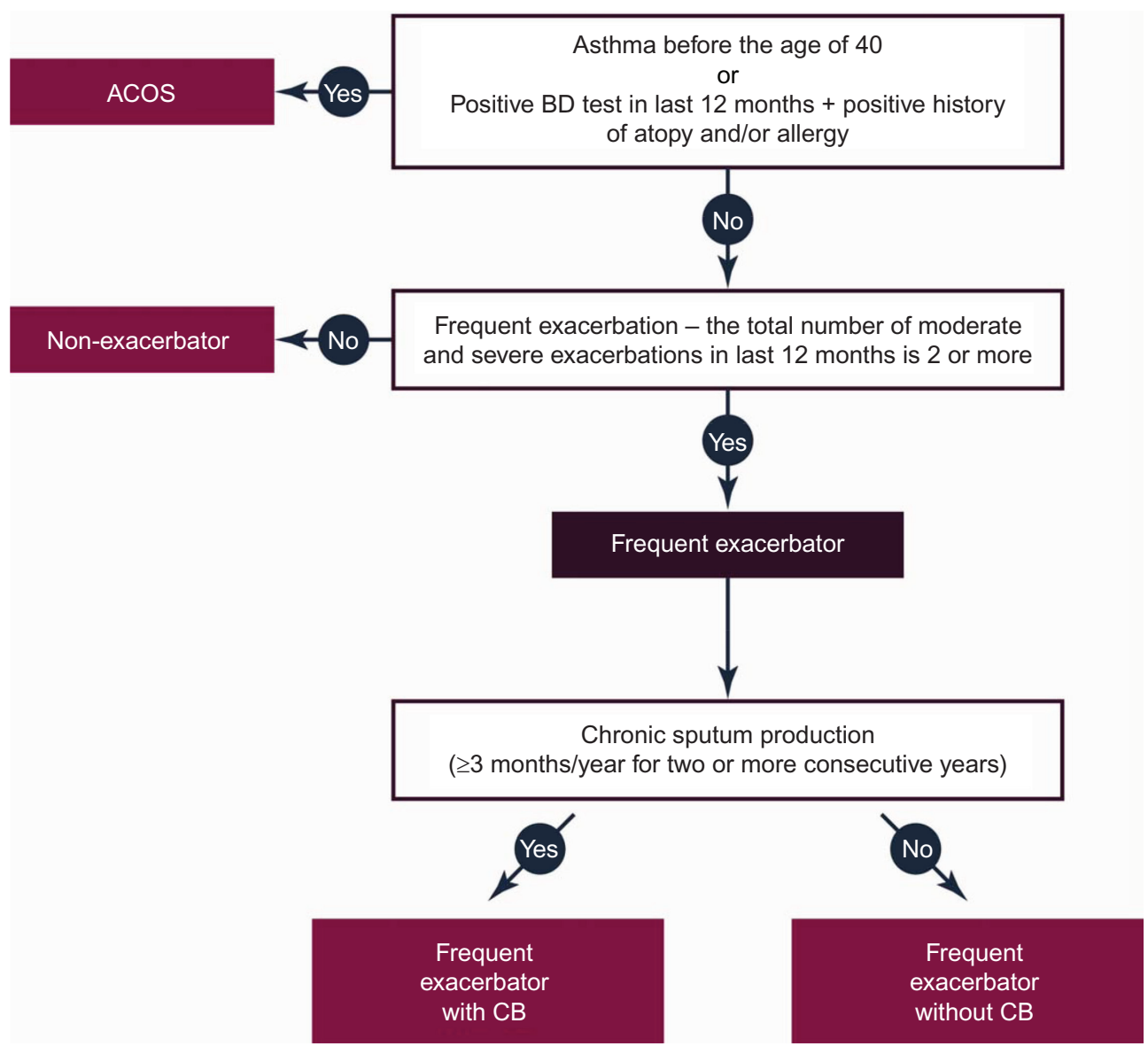

Figure 2 Simplified clinical definition of COPD phenotypes proposed by Marc Miravitlles, which is used in the POPE Study.

Note: Copyright (C) 2016. Dove Medical Press. Zbozinkova Z, Barczyk A, Tkacova R, et al. POPE study: rationale and methodology of a study to phenotype patients with COPD in Central and Eastern Europe. Int J Chron Obstruct Pulmon Dis. In press 2016. ${ }^{75}$

Abbreviations: ACOS, asthma and COPD overlap syndrome; BD, bronchodilator; CB, chronic bronchitis; COPD, chronic obstructive pulmonary disease; POPE Study, phenotypes of COPD in Central and Eastern Europe study.

subjects labeled and treated as having COPD do not have any spirometry confirmation of this condition (Table 2). Recently, Llordés et al have performed a population-based, epidemiological study, conducted in a primary care setting among subjects older than 45 years with a positive history of smoking. A total of 1,738 individuals ( $84.4 \%$ males) with a mean age of 59.9 years took part. The prevalence of COPD was $24.3 \%$, with an overall underdiagnosis of $56.7 \%$. Generally, patients with COPD were older, more frequently male, with a lower body mass index, a longer history of smoking, lower educational level, occupational exposure in history, and more cardiovascular comorbidities. On the other hand, $15.6 \%$ of individuals with a diagnosis of COPD did not have any airflow obstruction pattern; they were misdiagnosed as having COPD. ${ }^{57}$ Similar results are apparent in the analysis published by Lamprecht et al from the BOLD Collaborative Research Group, the EPI-SCAN Team, the PLATINO Team, and the PREPOCOL Study Group. Among 30,874 participants (mean age 56 years, $55.8 \%$ females,
$22.9 \%$ current smokers), there existed varied population prevalence of COPD from $3.6 \%$ in Colombia to $19.0 \%$ in South Africa. Globally, $81.4 \%$ of COPD cases confirmed by a spirometry were previously undiagnosed. There were significant differences between countries: $50.0 \%$ of underdiagnosed individuals in the US versus $98.3 \%$ of underdiagnosed subjects in Nigeria (Table 2). A greater chance of being undiagnosed with COPD was found in the male sex and those with younger age, never and current smoking, lower level of education, less severe airflow limitation, and absence of spirometry in the medical history ${ }^{58}$ Community pharmacologists have easy access to potentially undiagnosed COPD individuals. In the population of 1,456 Spanish subjects identified as having "high risk" from COPD (with three or more "yes" replies to GOLD-proposed questionnaire: a) older than 40 years; b) smoker/ex-smoker; c) more breathlessness than peers of the same age; d) chronic cough; and e) chronic expectoration), the presence of pre-BD airflow limitation in $282(19.8 \%)$ of them was confirmed. These 
Table 2 Underdiagnosis of COPD

\begin{tabular}{|c|c|c|c|c|c|c|c|c|}
\hline Study type & Reference & $\begin{array}{l}\text { Participants } \\
\text { (n) }\end{array}$ & $\begin{array}{l}\text { Age } \\
\text { (yrs) }\end{array}$ & Subjects & $\begin{array}{l}\text { COPD } \\
\text { diagnosed by: }\end{array}$ & $\begin{array}{l}\text { COPD } \\
\text { prevalence }(\%)\end{array}$ & $\begin{array}{l}\text { Underdiagnosis } \\
(\%)\end{array}$ & $\begin{array}{l}\text { Overdiagnosis } \\
(\%)\end{array}$ \\
\hline Population based & $\begin{array}{l}\text { Llordés } \\
\text { et } \mathrm{al}^{57}\end{array}$ & 1,738 & 59.9 & $\begin{array}{l}\text { Smokers } \\
\geq 45 \text { yrs }\end{array}$ & $\begin{array}{l}\text { Questionnaire } \\
\text { and post-BD } \\
\text { spirometry }^{\mathrm{a}}\end{array}$ & 24.3 & 56.7 & 15.6 \\
\hline $\begin{array}{l}\text { Population based, } \\
\text { pooled data }\end{array}$ & $\begin{array}{l}\text { Lamprecht } \\
\text { et } \mathrm{al}^{58}\end{array}$ & 30,874 & 56.0 & $\begin{array}{l}\text { Adults } \\
\geq 40 \mathrm{yrs}\end{array}$ & $\begin{array}{l}\text { Questionnaire } \\
\text { and post-BD } \\
\text { spirometry }^{\mathrm{b}}\end{array}$ & $9.7(3.6-19.0)^{\#}$ & 81.4 & NA \\
\hline Cross-sectional & $\begin{array}{l}\text { Castillo } \\
\text { et } \mathrm{al}^{59}\end{array}$ & 1,456 & 54.2 & $\begin{array}{l}\text { High-risk } \\
\text { adults }\end{array}$ & $\begin{array}{l}\text { Questionnaire } \\
\text { and pre-BD } \\
\text { spirometryc }^{c}\end{array}$ & 19.8 & NA & NA \\
\hline Prospective & $\begin{array}{l}\text { Almagro } \\
\text { et } a^{66}\end{array}$ & 133 & 63.0 & $\begin{array}{l}\text { CAD after } \\
\text { PCI }\end{array}$ & $\begin{array}{l}\text { Post-BD } \\
\text { spirometry }^{a}\end{array}$ & 24.8 & 81.8 & NA \\
\hline Retrospective & $\begin{array}{l}\text { Zhang } \\
\text { et al }\end{array}$ & 3,263 & 65.0 & $\begin{array}{l}\text { Lung cancer } \\
\text { subjects }\end{array}$ & $\begin{array}{l}\text { Pre-BD } \\
\text { spirometryc }\end{array}$ & 21.6 & 92.9 & NA \\
\hline Cross-sectional & $\begin{array}{l}\text { Zwar } \\
\text { et al }{ }^{83}\end{array}$ & 445 & 65.0 & $\begin{array}{l}\text { GP's suspicion } \\
\text { of COPD }\end{array}$ & $\begin{array}{l}\text { Pre-BD } \\
\text { spirometryc }\end{array}$ & 57.8 & NA & 40.0 \\
\hline Cross-sectional & $\begin{array}{l}\text { Hill } \\
\text { et al }{ }^{84}\end{array}$ & 1,003 & 60.0 & $\begin{array}{l}\text { Smokers } \\
\geq 40 \text { yrs }\end{array}$ & $\begin{array}{l}\text { Questionnaire } \\
\text { and pre-BD } \\
\text { spirometry }^{d}\end{array}$ & 20.7 & 67.3 & NA \\
\hline Cross-sectional & $\begin{array}{l}\text { Roberts } \\
\text { et } \mathrm{al}^{85}\end{array}$ & 503 & 63.8 & $\begin{array}{l}\text { GP's suspicion } \\
\text { of COPD }\end{array}$ & $\begin{array}{l}\text { Pre-BD } \\
\text { spirometryc }\end{array}$ & 60.0 & NA & 28.0 \\
\hline Cross-sectional & $\begin{array}{l}\text { Bednarek } \\
\text { et } \mathrm{al}^{86}\end{array}$ & 2,250 & 56.7 & Adults $\geq 40$ yrs & $\begin{array}{l}\text { Questionnaire } \\
\text { and pre-BD } \\
\text { spirometry }^{c}\end{array}$ & 9.3 & 81.4 & NA \\
\hline
\end{tabular}

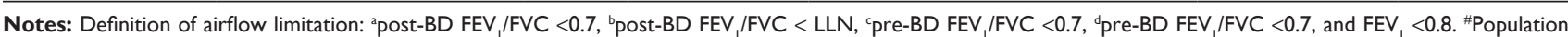
prevalence of COPD ranged from 3.6\% in Barranquilla, Colombia, to 19.0\% in Cape Town, South Africa.

Abbreviations: BD, bronchodilator; CAD, coronary artery disease; COPD, chronic obstructive pulmonary disease; FEV , forced expiratory volume in I second; FVC, forced volume vital capacity; GP's, general practitioners; NA, not available; PCI, percutaneous coronary intervention; yrs, years.

data were obtained through cross-sectional, descriptive, uncontrolled, remotely supported study in 100 community pharmacologist workplaces in Barcelona, Spain. ${ }^{59}$

Zhang et al showed that underdiagnosis and undertreatment of COPD remain quite common in lung cancer patients. Medical records of hospitalized lung cancer patients in Zhongshan Hospital, Fudan University (general teaching hospital in the east coast of the People's Republic of China), were retrospectively reviewed between January 2006 and December 2010. The prevalence of spirometry-defined COPD in hospitalized individuals with lung cancer was $21.6 \%$ $(705 / 3,263)$. Out of these 705 patients, only $50(7.1 \%)$ were previously diagnosed as having COPD, while $655(92.9 \%)$ were undiagnosed. Smoking history $(10.3 \%$ vs $1.5 \%)$ and presence of respiratory symptoms ( $24.8 \%$ vs $2.2 \%)$ promote correct COPD diagnosis. ${ }^{60}$ Moreover, many COPD exacerbations go unreported and untreated. ${ }^{61,62}$ Electronic symptom diaries or the EXAcerbations of Chronic pulmonary disease Tool (EXACT) scale can be used to detect such undiagnosed events, using definitions that depend on a sustained worsening of respiratory symptoms for 2 consecutive days. ${ }^{63,64}$

\section{Difficulty diagnosing COPD} Where are the missing COPD patients?

Comparisons with age-matched population data showed that people with COPD spend extended periods in sedentary behaviors, have limited engagement in physical activity (walking and exercising), have high health care needs (medical appointments), and experience difficulties associated with activities of daily living (personal self-care and chores) compared to non-COPD subjects in the similar age. The majority of undiagnosed COPD patients are at home, without intensive social contact; often in nursing homes; or at senior-assisted living facilities. ${ }^{65}$

Potentially promising "sources" of new, still undiagnosed, COPD subjects can be oncology and cardiology clinics caring for subjects with lung cancers and coronary artery disease (CAD). As mentioned earlier, Chinese colleagues retrospectively confirmed the presence of COPD in almost $22 \%$ of subjects being treated for pulmonary malignancy; a notable part of them (93\%) were not previously diagnosed. ${ }^{60}$ The Spanish group (Almagro et al) has recently published 
the first robust prospective study related to this issue. They consecutively examined 133 patients after percutaneous coronary intervention due to CAD (63.0 years). One month after percutaneous coronary intervention, $24.8 \%$ of them met spirometry criteria for COPD, of whom $81.8 \%$ were undiagnosed. CAD subjects with COPD were older, had more coronary vessels affected, and had a greater history of previous myocardial infarction. Subsequent follow-up (median 934 days) confirmed poor prognostic impact of COPD on all-cause mortality (hazard ratio [HR] 8.85) and cardiovascular morbidity (HR 1.87). These differences remained after adjustment for sex, age, number of coronary vessels affected, and previous myocardial infarct. ${ }^{66}$

Finally, possible source of new cases can be found in patients examined by computed tomography (CT) of the thorax. Incidental CT findings of emphysema and airway thickening, as seen on routine diagnostic chest CT scans performed for several nonpulmonary clinical indications, are associated with future severe exacerbations of COPD resulting in hospitalization or death. This statement was fully confirmed by a large multicentre prospective case-cohort study comprising 6,406 subjects who underwent routine diagnostic chest CT for nonpulmonary indications, published recently by PROVIDI Study group. Using a case-cohort approach was visually graded CT scans from cases and a random sample of $\sim 10 \%$ of the baseline cohort $(n=704)$ for emphysema severity (range 0-20), airway thickening (range 0-5), and bronchiectasis (range 0-5). During a median follow-up of 4.4 years, 338 of COPD events were identified. The risk of experiencing a future acute exacerbation of COPD resulting in hospitalization or death was significantly increased in subjects with severe emphysema (score $\geq 7$ ) and severe airway thickening (score $\geq 3$ ). The respective HRs were 4.6 and 5.9. Severe bronchiectasis (score $\geq 3$ ) was not significantly associated with increased risk of adverse events (HR 1.5). Morphological correlates of COPD such as emphysema and airway thickening detected on routine CT scans obtained for other nonpulmonary indications are strong independent predictors of subsequent development of acute exacerbations of COPD resulting in hospitalization or death. ${ }^{67}$

\section{Why do we have problems with correct diagnosis of elderly COPD patients?}

The prevalence of COPD dramatically increases with age (global median age of patients reaches 65-67 years), and COPD complicated by chronic respiratory failure may be considered as a frequent geriatric condition. Unfortunately, most clinical cases in the elderly remain undiagnosed because of: a) atypical clinical presentation; b) symptoms overlapping due to coexistence of COPD and other prominent comorbidities; and c) difficulty with respiratory function evaluation of seniors (spirometry needs a high level of adherence and activity of all examined subjects). Logically, the disease is commonly unrecognized and undertreated. This is expected to noticeably impact the health status of unrecognized COPD patients because a timely therapy could mitigate the distinctive and important effects of COPD on the health status. Besides having major prognostic implications, comorbidities also play a pivotal role in conditioning both the health status and the therapy of COPD. Several problems affect the overall quality of therapy for the elderly with COPD, and current guidelines as well as results from pharmacological trials only to some extent apply to these patients. Finally, physicians of different specialties care for the elderly COPD patient: physicians' specialties largely determine the approach to differential diagnosis.

As such, COPD, in itself a syndrome, becomes difficult to diagnose and to manage in the elderly. Interdisciplinary efforts are desirable to provide the practicing physician with a multidisciplinary guide to the identification and treatment of COPD. ${ }^{1,68}$

\section{Physician's training in diagnosing COPD - ability to carry out spirometry}

Educated physicians (especially, pulmonary specialists) are able to distinctly improve appropriate diagnosis of COPD. The correct diagnosis of COPD subjects among respiratory specialists (34.8\%) was significantly higher than in nonrespiratory physicians $(2.9 \%)$ in the recent Chinese study ${ }^{60}$ The 1-hour training course and a spirometry evaluation could increase the ability of a nonrespiratory physician to correctly diagnose and treat COPD patients. This statement was clearly confirmed by a recent study of Cai et al from the Hunan province in the South Central People's Republic of China. A total of 225 internists worked at eight secondary hospitals, which previously did not have spirometry technology available, and underwent a 1-hour training session on the Chinese COPD guidelines. The mean scores of COPD knowledge (out of 100) before and after the training course were $53.1 \pm 21.7$ and $93.3 \pm 9.8$, respectively. Subsequently, 18 internists and 307 patients without a COPD diagnosis participated in the spirometry intervention. Based on the spirometry results, the prevalence of COPD was $38.8 \%$. Nonrespiratory physicians (after 1-hour training) correctly identified the presence of COPD without spirometry data 
in $76.6 \%$ cases; this increased to $97.4 \%$ cases once spirometry data were available. Spirometry data also significantly improved the ability of physicians to correctly grade COPD severity. In the 119 patients who were determined by spirometry to have COPD, treatments prescribed to patients before nonrespiratory physicians were given spirometry results were compared to treatments prescribed after the results were made available. Based on the recommendations of GOLD and the Chinese COPD guidelines, the percentage of correct COPD treatment prescribed improved from $18.5 \%(22 / 119)$ to $84.0 \%(100 / 119)$. The changes in prescriptive patterns were most evident in the groups of patients with moderate and severe COPD. ${ }^{69}$

It was shown that adequately trained and supported community pharmacists (4-day interactive training focused on spirometry and web assistance) can effectively identify individuals at high risk of having COPD, and thereafter, they can perform spirometry evaluation of this high-risk cohort. Good quality, clinically acceptable pre-BD spirometries were captured in $69.4 \%$ of the cases. ${ }^{59}$

\section{Physician's awareness of diagnostic and treatment guidelines and the role of Continuing Medical Education \\ Real-life implementation of guidelines in the COPD field}

The best available evidence-based guidelines can improve the positive clinical impact of COPD management. Identifying the target audience, deciding what type of evidence to include, and establishing, reporting, and publishing guidelines are only the initial steps. Educational activity and disseminating, implementing, evaluating, and updating these guideline documents are the necessary next steps toward routine medical application. ${ }^{70}$ We did not know if COPD-related guidelines and recommendations are adequately a) explained and b) followed by respiratory physicians and general practitioners (GPs) around the globe. Two multicentre, cross-sectional studies, related to understanding of self-reported COPD guidelines and translation of this knowledge into routine practice, were performed in the Czech Republic. In this country (like in Slovakia, Hungary, or Serbia), COPD patients are predominantly cared for by respiratory physicians $(95 \%$ of COPD subjects) and a minority of COPD individuals (up to $5 \%$ ) are in the GP's care. ${ }^{54}$ The primary objective of the first study (conducted in 2012) was to examine the extent to which GOLD 2011 was used among Czech respiratory specialists, in particular with regard to the correct A-D classification of their COPD patients. The secondary objective was to explore what effect an erroneous classification has on the inadequate use of ICS. Based on 1,355 patient electronic forms, a discrepancy between the subjective and objective classifications was found in $32.8 \%$ of cases. The most common reason for incorrect classification was an error in the assessment of symptoms, which resulted in underestimation in $23.9 \%$ of cases and overestimation in $8.9 \%$ of the patients' records examined. The specialists seeing $>120$ patients/month were most likely to misclassify their condition and were found to have done so in $36.7 \%$ of all patients seen. While examining the subjectively driven ICS prescription, it was found that $19.5 \%$ of patients received ICS not according to guideline recommendations, while in $12.2 \%$ of cases, the ICS were omitted, contrary to guideline recommendations. It was therefore concluded that Czech pulmonary specialists tend to either underprescribe or overuse ICS. Women were overprescribed ICS more frequently than men. ${ }^{39}$ Similar to Czech results, Sarc et al reported that overprescription of ICS reached $25 \% .^{71}$ Overtreatment with ICS has also been reported elsewhere. ${ }^{72-74}$

In May 2013, the CPPS published the new national guidelines based on the simultaneous use of GOLD principles and COPD phenotypes (Table 1). The implementation rate of this innovative approach into the routine practice of respiratory specialists was the main purpose of the second study (with similar design and respondent cohort) 2 years ago. The data regarding 1,323 consecutive COPD subjects (413 males, $\mathrm{FEV}_{1} 52.6 \%$, $18.3 \%$ nonsmokers) from 86 pulmonary specialists were obtained (half of them from nonhospital services, $17 \%$ from university hospitals). Twenty-three percent of all Czech respiratory physicians, from all the 14 districts of the Czech Republic took part. The majority declared routine use of GOLD categories and clinical phenotypes as well. Simple clinical assessment of COPD phenotypes showed $16.2 \%$ ACOS subjects, $62.3 \%$ nonexcerbators, and $18.4 \%$ and $3.2 \%$ exacerbators with and without bronchitis. More sophisticated procedure used on 409 participants (with recent $\mathrm{CT}$ available) found pulmonary emphysema in $65.4 \%$ and COPD-associated bronchiectasis (bronchiectasis-COPD overlap syndrome) in $15.7 \%$. One-third of the patients had two or more phenotypical labels. Long-term therapy of COPD consisted of long-acting $\beta_{2}$-agonists $75.9 \%$, long-acting muscarinic antagonists $57.5 \%$, ICS $46.2 \%$, theophyllines $45.7 \%$, mucoactive drugs $15.7 \%$, roflumilast $8.3 \%$, and antibiotics $1 \%$. One year later, the Czech doctors found classification according to GOLD criteria slightly more 
preferable rather than by phenotypes when prescribing ICS, roflumilast, and mucoactive drugs. Approximately half of the patients $(49 \%-58 \%)$ had their medication prescribed correctly both by GOLD and phenotypes. The self-reported acknowledgment of the phenotypically centered CPPS guidelines among specialists was satisfactory. Despite high awareness of the new guidelines, the real-life implementation was insufficient as treatment habits did not fully reflect the phenotypical approach. ${ }^{13}$

\section{Role of Continuing Medical Education and successful strategies in training of health care providers}

GPs as the first-line physicians provide care for the vast majority of COPD individuals in both the developed and developing countries. Despite the availability of clinical practice guidelines for COPD, their influence on daily practice is unclear. A study in Birmingham, AL, USA, focused on examination of primary care decision-making, perceptions, and educational needs relating to COPD. In all, 784 practicing GPs were used in the analysis. On average, physicians estimated that $12 \%$ of their patients had COPD. Although $55 \%$ of physicians were aware of major COPD guidelines, only $25 \%$ used them to guide decision-making. Self-identified guidelines showed that users of Continuing Medical Education (CME) guidelines were more likely to order spirometry for subtle respiratory symptoms (74\% vs $63 \%$ ) to initiate therapy for mild symptoms ( $86 \%$ vs $77 \%$ ) and to choose long-acting BDs for persistent dyspnea associated with COPD (50\% vs $32 \%){ }^{76}$

Eastern European countries have two most important nonmalignant chronic diseases responsible for the majority of death: congestive heart failure and COPD. Peabody et al published a national assessment of the quality of clinical care practice in the Ukrainian health care system.

In all, 136 hospitals and 125 outpatient settings were surveyed; 1,044 physicians were interviewed and completed clinical performance and value vignettes. On average, physicians scored $47.4 \%$ on the vignettes. Younger, female physicians provide a higher quality of care, as well as those who have completed the recent CME program. Higher quality of care was associated with significantly better health outcomes. ${ }^{77}$

In addition, optimal management of COPD subjects depends on adherence to multiple devices used for inhaled medications. The critical errors committed during inhaler use can reduce treatment effectiveness. Outpatient education in inhaler technique remains widely inconsistent due to: a) time- consuming character of careful inhalation training; b) limited resources; and c) inadequate health care provider's knowledge. ${ }^{78}$ To determine whether a simple, two-session inhaler education program can improve physician attitudes toward inhaler education in primary care practice, a small-group hands-on device training session for GPs in British Columbia and Alberta was arranged. Sessions were spaced 1-3 months apart. All critical errors were corrected in the first session. Before the program, only $49 \%$ of GPs reported providing some form of inhaler use education in their practices and only $10 \%$ felt fully competent to teach patients inhaler technique. After the program, $98 \%$ rated their inhaler teaching as good to excellent. All stated that they could teach inhaler technique within 5 minutes. Observation of GPs during the second session by certified respiratory educators found that none made critical errors and all had excellent technique. ${ }^{79}$

\section{Future prospects/conclusion}

COPD is still a widely underdiagnosed and undertreated pulmonary condition. The routine use of quality spirometry in primary care in subjects with respiratory symptoms should reduce underdiagnosis of COPD. ${ }^{82}$ More comprehensive spread of health care professionals' education and correct use and adequate interpretation of spirometry assessment could reduce the incidence of undiagnosed cases, particularly in smoking women, elderly subjects, and individuals being treated for lung cancer, CAD, heart failure, and diabetes. A number of studies have evaluated the accuracy of screening tests for COPD in primary care. The results of systematic review and meta-analysis of the diagnostic accuracy of screening tests for COPD confirmed by spirometry among individuals aged $\geq 35$ years with no prior diagnosis of COPD were presented. Bivariate meta-analysis of sensitivity and specificity was performed. Ten studies were included. Eight assessed screening questionnaires (the COPD Diagnostic Questionnaire [CDQ] was the most evaluated), four assessed handheld flow meters (COPD-6), and one assessed their combination. Among ever smokers, the CDQ had a pooled sensitivity of $64.5 \%$ and a specificity of $65.2 \%$, and handheld flow meters had a sensitivity of $79.9 \%$ and a specificity of $84.4 \%$. Handheld flow meters demonstrated higher test accuracy than the CDQ for COPD screening in primary care. The choice of alternative screening tests within whole screening programs should now be fully evaluated in future better designed studies. ${ }^{80}$

More research on strategies to reduce the overwhelming phenomenon of COPD underdiagnosis is needed. COPD underdiagnosis has remained high in many countries, even after years of multiple interventions. ${ }^{58}$ Apart from primary 
care as the central venue to screen for COPD, other options might be considered, such as community pharmacists trained in spirometry or active searching for COPD associated with the presence of comorbid disease (lung cancer, CAD, heart failure, and diabetes). ${ }^{59,66-68}$

The Finnish National Prevention and Treatment Program for Chronic Bronchitis and COPD is an example of a good approach and new strategy in finding COPD. It includes the widespread (not only elderly males with smoking history) use of spirometry testing combined with smoking cessation efforts. $^{81}$

Practice guidelines and CME programs have not yet adequately reached many physicians. Because guidelines appear to influence clinical decision-making, efforts to propagate them more broadly are needed. Future CME education should present diagnostic algorithms tailored to both primary care settings and specialists, assess and strengthen spirometry interpretation skills, and discuss a reasoned approach to treatment strategy. Internet-based CME formats may be useful for reaching physicians in many areas.

\section{Disclosure}

VK presented the lectures at symposia, was sponsored by, and received fees for advisory board participation and travel grants from AstraZeneca, Berlin-Chemie, Boehringer Ingelheim, GlaxoSmithKline, Medicom, Mundipharma, Novartis, and Takeda. He received research grants from AstraZeneca, Boehringer Ingelheim and Novartis. BN, ZZ, and $\mathrm{KH}$ are employees of the Institute of Biostatistics and Analyses, Masaryk University. The Institute of Biostatistics and Analyses has received research grants from (in alphabetical order) AstraZeneca, Bayer, Boehringer Ingelheim, GlaxoSmithKline, Novartis, Pfizer, and Roche. The authors report no conflicts of interest related to this work.

\section{References}

1. Global Initiative for Chronic Obstructive Lung Disease [webpage on the Internet]. Global Strategy for the Diagnosis, Management, and Prevention of Chronic Obstructive Pulmonary Disease [updated January, 2014]. Available from: http://www.goldcopd.org/uploads/users/files/ GOLD_Report_2014_Jun11.pdf. Accessed September 30, 2015.

2. Anon C. Terminology, definitions, and classification of chronic pulmonary emphysema and related conditions: a report of the conclusions of a Ciba guest symposium. Thorax. 1959;14:286-299.

3. Corhay JL. Personalized medicine: chronic obstructive pulmonary disease treatment. Rev Med Liege. 2015;70(5-6):310-315.

4. Andersson M, Stridsman C, Rönmark E, Lindberg A, Emtner M. Physical activity and fatigue in chronic obstructive pulmonary disease a population based study. Respir Med. 2015;109(8):1048-1057.

5. Liu Y, Pleasants R, Croft J, et al. Smoking duration, respiratory symptoms, and COPD in adults aged $\geq 45$ years with a smoking history. Int J Chron Obstruct Pulmon Dis. 2015;10:1409-1416.
6. World Health Organisation [webpage on the Internet]. Chronic Obstructive Pulmonary Disease (COPD) [updated October, 2013]. Available from: http://www.who.int/respiratory/copd/en/. Accessed August 2, 2015.

7. Menezes AM, Jardim JR, Pérez-Padilla R, et al. Prevalence of chronic obstructive pulmonary disease and associated factors: the PLATINO Study in Sao Paulo, Brazil. Cad Saude Publica. 2005;21(5): 1565-1573.

8. Rycroft CE, Heyes A, Lanza L, Becker K. Epidemiology of chronic obstructive pulmonary disease: a literature review. Int J Chron Obstruct Pulmon Dis. 2012;7:457-494.

9. Buist AS, McBurnie MA, Vollmer WM, et al; BOLD Collaborative Research Group. International variation in the prevalence of COPD (the BOLD Study): a population-based prevalence study. Lancet. 2007;370(9589):741-750.

10. Kojima S, Sakakibara H, Motani S, et al. Incidence of chronic obstructive pulmonary disease, and the relationship between age and smoking in a Japanese population. J Epidemiol. 2007;17(2):54-60.

11. de Marco R, Accordini S, Marcon A, et al; European Community Respiratory Health Survey (ECRHS). Risk factors for chronic obstructive pulmonary disease in a European cohort of young adults. Am J Respir Crit Care Med. 2011;183(7):891-897.

12. Moreira GL, Gazzotti MR, Manzano BM, et al. Incidence of chronic obstructive pulmonary disease based on three spirometric diagnostic criteria in Sao Paulo, Brazil: a nine-year follow-up since the PLATINO prevalence study. Sao Paulo Med J. 2015;133(3):245-251.

13. Koblizek V, Zigmond J, Pecen L, et al. Implementation of COPD Phenotypes in Real Life. Thematic Poster Session. European Respiratory Society Congress 2015; Amsterdam, the Netherlands.

14. Torres-Duque C, Maldonado D, Pérez-Padilla R, et al; Forum of International Respiratory Studies (FIRS) Task Force on Health Effects of Biomass Exposure. Biomass fuels and respiratory diseases: a review of the evidence. Proc Am Thorac Soc. 2008;5(5):577-590.

15. Hnizdo E, Sullivan PA, Bang KM, Wagner G. Association between chronic obstructive pulmonary disease and employment by industry and occupation in the US population: a study of data from the Third National Health and Nutrition Examination Survey. Am J Epidemiol. 2002;156(8):738-746.

16. Aryal S, Diaz-Guzman E, Mannino DM. Influence of sex on chronic obstructive pulmonary disease risk and treatment outcomes. Int J Chron Obstruct Pulmon Dis. 2014;9:1145-1154.

17. Miravitlles M, Soler-Cataluña JJ, Calle M, et al. Spanish guideline for COPD (GesEPOC). Update 2014. Arch Bronconeumol. 2014;50 (suppl 1):1-16.

18. Qaseem A, Wilt TJ, Weinberger SE, et al; American College of Physicians; American College of Chest Physicians; American Thoracic Society; European Respiratory Society. Diagnosis and management of stable chronic obstructive pulmonary disease: a clinical practice guideline update from the American College of Physicians, American College of Chest Physicians, American Thoracic Society, and European Respiratory Society. Ann Intern Med. 2011;155(3):179-191.

19. Miller MR, Hankinson J, Brusasco V, et al; ATS/ERS Task Force. Standardisation of spirometry. Eur Respir J. 2005;26(2):319-338.

20. Pellegrino R, Viegi G, Brusasco V, et al. Interpretative strategies for lung function tests. Eur Respir J. 2005;26(5):948-968.

21. Celli B, Cote C, Marin J, et al. The body-mass index, airflow obstruction, dyspnea and exercise capacity index in chronic obstructive pulmonary disease. N Engl J Med. 2004;350:1005-1012.

22. Celli B. Update on the management of COPD. Chest. 2008;133: 1451-1462.

23. O'Donnell D, Flüge T, Gerken F, et al. Effects of tiotropium on lung hyperinflation, dyspnoea and exercise tolerance in COPD. Eur Respir J. 2004;23:832-840.

24. Stridsman C, Lindberg A, Skär L. Fatigue in chronic obstructive pulmonary disease: a qualitative study of people's experiences. Scand J Caring Sci. 2014;28:130-138.

25. Karpman C, Benzo R. Gait speed as a measure of functional status in COPD patients. Int J Chron Obstruct Pulmon Dis. 2014;9:1315-1320. 
26. Koblizek V, Tomsova M, Cermakova E, et al. Impairment of nasal mucociliary clearance in former smokers with stable chronic obstructive pulmonary disease relates to the presence of a chronic bronchitis phenotype. Rhinology. 2011;49:397-406.

27. Arikan H, Savci S, Calik-Kutukcu E, et al. The relationship between cough-specific quality of life and abdominal muscle endurance, fatigue, and depression in patients with COPD. Int J Chron Obstruct Pulmon Dis. 2015;10:1829-1835.

28. Matkovic Z, Miravitlles M. Chronic bronchial infection in COPD. Is there an infective phenotype? Respir Med. 2013;107(1):10-22.

29. Hurst JR, Vestbo J, Anzueto A, et al; Evaluation of COPD Longitudinally to Identify Predictive Surrogate Endpoints (ECLIPSE) Investigators. Susceptibility to exacerbation in chronic obstructive pulmonary disease. N Engl J Med. 2010;363:1128-1138.

30. Wise RA, Anzueto A, Cotton D, et al; TIOSPIR Investigators. Tiotropium Respimat inhaler and the risk of death in COPD. $N$ Engl J Med. 2013;369:1491-1501

31. Cazzola M, MacNee W, Martinez FJ, et al; American Thoracic Society; European Respiratory Society Task Force on outcomes of COPD. Outcomes for COPD pharmacological trials: from lung function to biomarkers. Eur Respir J. 2008;31:416-469.

32. Molen T, Miravitlles M, Kocks J. COPD management: role of symptom assessment in routine clinical practice. Int J Chron Obstruct Pulmon Dis. 2013;8:461-471.

33. Han M, Muellerova H, Curran-Everett D, et al. GOLD 2011 disease severity classification in COPDGene: a prospective cohort study. Lancet Respir Med. 2013;1:43-50.

34. Yawn B, Duvall K, Peabody J, et al. The impact of screening tools on diagnosis of chronic obstructive pulmonary disease in primary care. Am J Prev Med. 2014;47:563-575.

35. Jones R, Price D, Ryan D, et al; Respiratory Effectiveness Group. Opportunities to diagnose chronic obstructive pulmonary disease in routine care in the UK: a retrospective study of a clinical cohort. Lancet Respir Med. 2014;2:267-276.

36. Lange P, Marott J, Vestbo J, et al. Prediction of the clinical course of chronic obstructive pulmonary disease, using the new GOLD classification: a study of the general population. Am J Respir Crit Care Med. 2012;186:975-981.

37. Chen CZ, Ou CY, Yu CH, Yang SC, Chang HY, Hsiue TR. Comparison of global initiative for chronic obstructive pulmonary disease 2013 classification and body mass index, airflow obstruction, dyspnea, and exacerbations index in predicting mortality and exacerbations in elderly adults with chronic obstructive pulmonary disease. J Am Geriatr Soc. 2015;63:244-250.

38. Sanchez-Salcedo P, Berto J, de-Torres J, et al. Lung cancer screening: fourteen year experience of the Pamplona early detection program (P-IELCAP). Arch Bronconeumol. 2015;51(4):169-176.

39. Koblizek V, Pecen L, Zatloukal J, et al. Real-life GOLD 2011 implementation: the management of COPD lacks correct classification and adequate treatment. PLoS One. 2014;9:e111078.

40. McGarvey L, Lee AJ, Roberts J, Gruffydd-Jones K, McKnight E, Haughney J. Characterisation of the frequent exacerbator phenotype in COPD patients in a large UK primary care population. Respir Med. 2015;109:228-237.

41. Casanova C, Marin J, Martinez-Gonzalez C, et al; COPD History Assessment In SpaiN (CHAIN) Cohort. New GOLD classification: longitudinal data on group assignment. Respir Res. 2014;15:3.

42. Jones P, Adamek L, Nadeau G, Banik N. Comparisons of health status scores with MRC grades in a primary care COPD population: implications for the new GOLD 2011 classification. Eur Respir J. 2013;42:647-654.

43. Casanova C, Marin JM, Martinez-Gonzalez C, et al; COPD History Assessment in Spain (CHAIN) Cohort. Differential effect of modified medical research council dyspnea, COPD assessment test, and clinical COPD questionnaire for symptoms evaluation within the new GOLD staging and mortality in COPD. Chest. 2015;148(1):159-168.
44. Koblizek V, Chlumsky J, Zindr V, et al. GOLD and Phenotypes: The New Czech COPD Guidelines. Thematic Poster Session. European Respiratory Society Congress 2015; Amsterdam, the Netherlands.

45. Bakke P, Rönmark E, Eagan T, et al. Recommendations for epidemiological studies on COPD. Eur Respir J. 2011;38:1261-1277.

46. Agusti A. The path to personalised medicine in COPD. Thorax. 2014;69:857-864.

47. Vestbo J. COPD: definition and phenotypes. Clin Chest Med. 2014;35:1-6.

48. Izquierdo-Alonso J, Rodriguez-Gonzálezmoro J, de Lucas-Ramos P, et al. Prevalence and characteristics of three clinical phenotypes of chronic obstructive pulmonary disease (COPD). Respir Med. 2013;107:724-731.

49. Miravitlles M, Calle M, Soler-Cataluña J. Clinical phenotypes of COPD. Identification, definition and implications for guidelines. Arch Bronconeumol. 2012;48:86-98.

50. National Institute for Health and Care Excellence [webpage on the Internet]. Chronic Obstructive Pulmonary Disease (updated) Clinical Guidelines CG101. Available from: http://www.nice.org.uk/CG101. Accessed February 19, 2015.

51. Kankaanranta H, Harju T, Kilpeläinen M, et al. Diagnosis and pharmacotherapy of stable chronic obstructive pulmonary disease: the finnish guidelines. Basic Clin Pharmacol Toxicol. 2015;116:291-307.

52. Gupta D, Agarwal R, Aggarwal A, et al; S. K. Jindal for the COPD Guidelines Working Group. Guidelines for diagnosis and management of chronic obstructive pulmonary disease: joint ICS/NCCP (I) recommendations. Lung India. 2013;30:228-267.

53. Khan J, Lababidi H, Al-Moamary M, et al. The Saudi guidelines for the diagnosis and management of COPD. Ann Thorac Med. 2014;9:55-76.

54. Koblizek V, Chlumsky J, Zindr V, et al; Czech Pneumological and Phthisiological Society. Chronic Obstructive Pulmonary Disease: official diagnosis and treatment guidelines of the Czech Pneumological and Phthisiological Society; a novel phenotypic approach to COPD with patient-oriented care. Biomed Pap Med Fac Univ Palacky Olomouc Czech Repub. 2013;157:189-201.

55. Soler-Cataluña J, Cosío B, Izquierdo J, et al. Consensus document on the overlap phenotype COPD-asthma in COPD. Arch Bronconeumol. 2012;48:331-337.

56. Montuschi P, Malerba M, Santini G, Miravitlles M. Pharmacological treatment of chronic obstructive pulmonary disease: from evidence-based medicine to phenotyping. Drug Discov Today. 2014;19:1928-1935.

57. Llordés M, Jaén A, Almagro P, et al. Prevalence, risk factors and diagnostic accuracy of COPD among smokers in primary care. COPD. 2015;12(4):404-412.

58. Lamprecht B, Soriano J, Studnicka M, et al; BOLD Collaborative Research Group, the EPI-SCAN Team, the PLATINO Team, and the PREPOCOL Study Group; BOLD Collaborative Research Group the EPI-SCAN Team the PLATINO Team and the PREPOCOL Study Group. Determinants of Underdiagnosis of COPD in national and international surveys. Chest. 2015;148(4):971-985.

59. Castillo D, Burgos F, Guayta R, et al; FARMAEPOC group. Airflow obstruction case finding in community-pharmacies: a novel strategy to reduce COPD underdiagnosis. Respir Med. 2015;109(4):475-482.

60. Zhang J, Zhou JB, Lin XF, Wang Q, Bai CX, Hong QY. Prevalence of undiagnosed and undertreated chronic obstructive pulmonary disease in lung cancer population. Respirology. 2013;18(2):297-302.

61. Langsetmo L, Platt R, Ernst P, Bourbeau J. Underreporting exacerbation of chronic obstructive pulmonary disease in a longitudinal cohort. Am J Respir Crit Care Med. 2008;177:396-401.

62. Xu W, Collet J, Shapiro S, et al. Negative impacts of unreported COPD exacerbations on health-related quality of life at 1 year. Eur Respir $J$. 2010;35:1022-1030.

63. Mackay AJ, Donaldson GC, Patel AR, Jones PW, Hurst JR, Wedzicha JA. Usefulness of the Chronic Obstructive Pulmonary Disease Assessment Test to evaluate severity of COPD exacerbations. Am J Respir Crit Care Med. 2012;185:1218-1224. 
64. Leidy NK, Murray LT. Patient-reported outcome (PRO) measures for clinical trials of COPD: the EXACT and E-RS. COPD. 2013;10:393-398.

65. Hunt T, Madigan S, Williams MT, Olds TS. Use of time in people with chronic obstructive pulmonary disease - a systematic review. Int $J$ Chron Obstruct Pulmon Dis. 2014;9:1377-1388.

66. Almagro P, Lapuente A, Yun S, et al. Underdiagnosis and prognosis of chronic obstructive pulmonary disease after percutaneous coronary intervention: a prospective study. Int J Chron Obstruct Pulmon Dis. 2015;10:1353-1361.

67. Jairam PM, van der Graaf Y, Lammers JW, Mali WP, de Jong PA; PROVIDI Study group. Incidental findings on chest CT imaging are associated with increased COPD exacerbations and mortality. Thorax. 2015;70:725-731.

68. Incalzi RA, Scarlata S, Pennazza G, Santonico M, Pedone C. Chronic obstructive pulmonary disease in the elderly. Eur J Intern Med. 2014;25(4):320-328.

69. Cai S, Qin L, Tanoue L, et al. Effects of one-hour training course and spirometry on the ability of physicians to diagnose and treat chronic obstructive pulmonary disease. PLoS One. 2015;10(2):e0117348.

70. Schünenmann H, Woodhead M, Anzueto A, et al; ATS/ERS Ad Hoc Committee on Integrating and Coordinating Efforts in COPD Guideline Development. A guide to guidelines for professional societies and other developers of recommendations. Introduction to integrating and coordinating efforts in COPD guideline development. An official ATS/ERS workshop report. Proc Am Thorac Soc. 2012;9(5): 215-218.

71. Sarc I, Jeric T, Ziherl K, et al. Adherence to treatment guidelines and long-term survival in hospitalized patients with chronic obstructive pulmonary disease. J Eval Clin Pract. 2011;17(4):37-43.

72. White P, Thorton H, Pinnock H, Georgopoulou S, Booth HP. Overtreatment of COPD with inhaled corticosteroids - implications for safety and costs: cross-sectional observational study. PLoS One. 2013;8(10): e75221.

73. Lucas A, Smeenk F, Smeele I, van Schayck C. Overtreatment with inhaled corticosteroids and diagnostic problems in primary care patients, an exploratory study. Fam Pract. 2008;25(2):86-91.

74. Roche N, Pribil C, van Ganse E, et al. Real-life use of fluticasone propionate/salmeterol in patients with chronic obstructive pulmonary disease: a French observational study. BMC Pulm Med. 2014;14(1):56.
75. Zbozinkova Z, Barczyk A, Tkacova R, et al. POPE study: rationale and methodology of a study to phenotype patients with COPD in Central and Eastern Europe. Int J Chron Obstruct Pulmon Dis. In press 2016.

76. Foster JA, Yawn BP, Maziar A, Jenkins T, Rennard SI, Casebeer L. Enhancing COPD management in primary care settings. MedGenMed. 2007;9(3):24.

77. Peabody J, Luck J, DeMaria L, Menon R. Quality of care and health status in Ukraine. BMC Health Serv Res. 2014;14:446.

78. Laube B, Janssens H, de Jongh F, et al; European Respiratory Society; International Society for Aerosols in Medicine. What the pulmonary specialist should know about the new inhalation therapies. Eur Respir J. 2011;37(6):1308-1331.

79. Leung J, Bhutani M, Leigh R, Pelletier D, Good C, Sin DD. Empowering family physicians to impart proper inhaler teaching to patients with chronic obstructive pulmonary disease and asthma. Can Respir J. 2015;22(5):266-270.

80. Haroon S, Jordan R, Takwoingi Y, Adab P. Diagnostic accuracy of screening tests for COPD: a systematic review and meta-analysis. $B M J$ Open. 2015;5(10):e008133.

81. Pietinalho A, Kinnula V, Sovijärvi A, et al. Chronic bronchitis and chronic obstructive pulmonary disease. The Finnish Action Programme, interim report. Respir Med. 2007;101(7):1419-1425.

82. Eaton T, Withy S, Garrett JE, Mercer J, Whitlock RM, Rea HH. Spirometry in primary care practice: the importance of quality assurance and the impact of spirometry workshops. Chest. 1999;116:416-423.

83. Zwar NA, Marks GB, Hermiz O, et al. Predictors of accuracy of diagnosis of chronic obstructive pulmonary disease in general practice. Med J Aust. 2011;195(4):168-171.

84. Hill K, Goldstein RS, Guyatt GH, et al. Prevalence and underdiagnosis of chronic obstructive pulmonary disease among patients at risk in primary care. CMAJ. 2010;182(7):673-678.

85. Roberts CM, Abedi MKA, Barry JS, et al. Predictive value of primary care made clinical diagnosis of chronic obstructive pulmonary disease (COPD) with secondary care specialist diagnosis based on spirometry performed in a lung function laboratory. Prim Health Care Res Dev. 2009; 10:49.

86. Bednarek M, Maciejewski J, Wozniak M et al. Prevalence, severity and underdiagnosis of COPD in the primary care setting. Thorax. 2008;63(5):402-407.
Advances in Medical Education and Practice

\section{Publish your work in this journal}

Advances in Medical Education and Practice is an international, peerreviewed, open access journal that aims to present and publish research on Medical Education covering medical, dental, nursing and allied health care professional education. The journal covers undergraduate education, postgraduate training and continuing medical education

\section{Dovepress}

including emerging trends and innovative models linking education, research, and health care services. The manuscript management system is completely online and includes a very quick and fair peer-review system. Visit http://www.dovepress.com/testimonials.php to read real quotes from published authors. 